\title{
Vertical transmission of Anaplasma platys and Leishmania infantum in dogs during the first half of gestation
}

\author{
Maria Stefania Latrofa ${ }^{1}$, Filipe Dantas-Torres ${ }^{1,2}$, Donato de Caprariis ${ }^{1}$, Cinzia Cantacessi ${ }^{3}$, Gioia Capelli ${ }^{4}$,
} Riccardo Paolo Lia ${ }^{1}$, Edward B. Breitschwerdt ${ }^{5}$ and Domenico Otranto ${ }^{1 *}$

\begin{abstract}
Background: Leishmania infantum is a canine zoonotic vector-borne protozoan pathogen transmitted by phlebotomine sand flies, whereas Anaplasma platys is a bacterium most likely transmitted by ticks. While vertical transmission of $L$. infantum from pregnant bitches to their offspring has been documented, thus far no studies have explored the possibility of vertical transmission of A. platys in dogs. This study investigated the occurrence of vertical transmission of $L$. infantum and A. platys in sheltered dogs during the first half of gestation, in an area of southern Italy characterised by a high incidence of infection by both pathogens.
\end{abstract}

Methods: The study population included 20 bitches ( $n=10$ pregnant, at $25-35$ days of pregnancy; $n=10$ nonpregnant), all subjected to ovariohysterectomy, which were examined for the presence of L. infantum and A. platys via cytological screening of bone marrow and whole blood samples. Infection by L. infantum and A. platys was also tested by immunofluorescence antibody test (IFAT) and quantitative real-time PCR (qPCR) targeting both pathogens. Selected tissue samples $(n=210)$ collected during surgical procedures from bitches and foetuses $(n=20)$ were assessed for the presence of $L$. infantum and A. platys by qPCR targeting a fragment of the kinetoplast minicircle DNA (KDNA) and the $16 \mathrm{~S}$ rRNA gene, respectively.

Results: Leishmania infantum DNA was not amplified from either uteri or ovaries from pregnant bitches or foetal tissue samples, whereas a subset of ovarian $(n=2)$ and uterine $(n=4)$ tissue samples from non-pregnant bitches were infected, with parasite loads of up to $3.09 \times 10$ and 7.51 parasite/PCR reaction, respectively. Conversely, uterine $(n=10)$ and ovarian $(n=8)$ tissues from both pregnant and non-pregnant bitches, together with a subset $(n=5)$ of foetal tissue samples were qPCR positive for A. platys. Leishmania infantum and A. platys nucleic acids were amplified from two uteri from nonpregnant bitches, with parasite loads of up to $2.32 \times 10^{-3}$ and 2.05 parasite/per PCR reaction, respectively.

Conclusions: Results from this study suggest that, in contrast to L. infantum, A. platys can be transmitted from pregnant dogs to their offspring during the first half of gestation. This hypothesis remains to be verified, for instance via direct observation of parasites in postpartum foetal tissues.

Keywords: Vertical transmission, Leishmania infantum, Anaplasma platys, Dog, Real-time PCR

\footnotetext{
*Correspondence: domenico.otranto@uniba.it

'Dipartimento di Medicina Veterinaria, Università degli Studi di Bari,

Valenzano, Italy

Full list of author information is available at the end of the article
} 


\section{Background}

Leishmania infantum (Kinetoplastida, Trypanosomatidae) and Anaplasma platys (Rickettsiales, Anaplasmataceae) are the causative agents of canine leishmaniosis (CanL) and canine infectious cyclic thrombocytopenia (CICT), respectively [1]. While $L$. infantum is primarily transmitted by phlebotomine sand flies of the genera Phlebotomus and Lutzomyia (Diptera, Psychodidae) [2], alternative modes of transmission have been investigated. These include blood transfusions $[3,4]$, as well as sexual $[5,6]$ and vertical transmission [7-12]. In particular, the latter has been hypothesized to occur in naturally infected dogs, resulting in both stillborn and live puppies [7-10]. Vertical transmission of L. infantum has been suggested to represent an important mechanism for the dissemination and maintenance of this pathogen, especially in the (apparent) absence of known competent vectors in non-endemic areas [10, 12-14]. For instance, a high prevalence of infection (i.e. $20 \%$ ) has been recorded in dogs from an area of the United States where the presence of phlebotomine sand fly vectors is yet to be confirmed [9, 10]. Rhipicephalus sanguineus (sensu lato) (Acari, Ixodidae), also referred to as the 'brown dog tick' or 'kennel tick', has been indicated as a potential vector of A. platys, mainly as a consequence of the detection of bacterial DNA in this arthropod species [15-18]. However, the role of ticks in the transmission of this bacterium has yet to be fully proven. Similarly, and to the best of our knowledge, thus far, no studies have assessed the potential occurrence of vertical transmission of $A$. platys in dogs, or of vertical transmission of $L$. infantum during the first half of gestation. Here, we explored the potential occurrence of vertical transmission of $L$. infantum and A. platys in naturally infected dogs, during early gestation, from a hyperendemic area for both pathogens.

\section{Methods}

\section{Ethics statement}

Animals involved in this study were enrolled in a sterilization program in 2008 and 2011 and were part of a previous study for the prevention and control of canine vector borne diseases [19]. The study above was carried out according to the guidelines for Good Clinical Practice (GCP GL9 VICH, 2000) and authorized by the Italian Ministry of Health (authorization number 72/2009C, $n^{\circ}$. 69062; 11/28/2008).

\section{Animals}

All animals enrolled in the present study were housed in a private dog shelter in Putignano, province of Bari, Apulia region, Italy, where the incidence of $L$. infantum (i.e. $47.6 \%$ ) and $A$. platys (i.e. $17.2 \%$ ) infections have previously been determined [19-21]. Twenty asymptomatic mixed-breed bitches were screened for infection by $L$. infantum and $A$. platys by whole blood and bone marrow cytological examination. In order to confirm the infection status, dogs were also tested by indirect immunofluorescent antibody test (IFAT) on whole blood (L. infantum) and pathogen DNA amplification from whole blood, bone marrow and skin samples (both L. infantum and A. platys) (Table 1). All bitches were subjected to clinical and abdominal ultrasound examinations for verification of the pregnancy status, followed by an ovariohysterectomy. Ten dogs (i.e. nine positive and one negative control) (aged from 7 months to 1 year old) were from 25 to 35 days pregnant (Table 1). Following surgery, two foetuses were randomly collected from the uteri of each pregnant bitch (Table 2) and foetal crown-rump length was measured to confirm their gestational age [22]. The remaining (age-matched) 10 dogs (i.e. nine positive and one negative control) enrolled in the study were nonpregnant bitches (Table 1).

\section{Sample collection and diagnostic procedures}

At the time of ovariohysterectomy, amniotic fluid and tissues samples $(n=210)$ including whole blood, skin, uterus, ovaries, placenta, liver, spleen, umbilical cord and bone marrow were collected from individual bitches and foetuses, in sterile conditions, and stored at $-20{ }^{\circ} \mathrm{C}$ until

Table 1 Distribution of Leishmania infantum and Anaplasma platys infections in different tissue samples from pregnant and nonpregnant bitches (Pos/Tot, \%)

\begin{tabular}{|c|c|c|c|c|c|c|c|c|c|}
\hline \multirow[t]{2}{*}{ Pathogen } & \multirow{2}{*}{\multicolumn{2}{|c|}{ Dogs }} & Blood & Bone marrow & Skin & Uterus & Ovary & Placentae & Total \\
\hline & & & Pos/Tot & Pos/Tot & Pos/Tot & Pos/Tot & Pos/Tot & Pos/Tot & Pos/Tot (\%) \\
\hline \multicolumn{10}{|l|}{ L. infantum } \\
\hline & Pregnant bitches & $(n=9)$ & $1 / 9$ & $7 / 9$ & $9 / 9$ & $0 / 9$ & $0 / 9$ & $1 / 9$ & 18/54 (33.3) \\
\hline & Non-pregnant bitches & $(n=9)$ & $2 / 9$ & $5 / 9$ & $4 / 9$ & $4 / 9$ & $2 / 9$ & - & $17 / 45(37.8)$ \\
\hline & Total Pos/Tot (\%) & & $3 / 18(16.7)$ & $12 / 18(66.7)$ & 13/18 (72.2) & $4 / 18(22.2)$ & $2 / 18(11.1)$ & $1 / 9(11.1)$ & $35 / 99(35.3)$ \\
\hline \multicolumn{10}{|l|}{ A. platys } \\
\hline & Pregnant bitches & $(n=9)$ & $3 / 9$ & $4 / 9$ & $3 / 9$ & $3 / 9$ & $2 / 9$ & $1 / 9$ & $16 / 54(29.6)$ \\
\hline & Non-pregnant bitches & $(n=9)$ & $0 / 9$ & $4 / 9$ & $1 / 9$ & $7 / 9$ & $6 / 9$ & - & $18 / 45(40)$ \\
\hline & Total Pos/Tot (\%) & & $3 / 18(16.6)$ & 8/18 (44.4) & $4 / 18(22.2)$ & $10 / 18(55.5)$ & $8 / 18(44.4)$ & $1 / 9(11.1)$ & $34 / 99$ (34.3) \\
\hline
\end{tabular}


Table 2 Distribution of Leishmania infantum and Anaplasma platys infection in foetal tissue from naturally infected pregnant bitches. Starting Quantity (SQ) mean value of parasite load per PCR reaction

\begin{tabular}{|c|c|c|c|c|c|c|c|c|c|c|}
\hline \multirow[t]{2}{*}{ Foetuses } & \multicolumn{2}{|c|}{ Bone marrow } & \multicolumn{2}{|l|}{$\underline{\text { Liver }}$} & \multicolumn{2}{|l|}{ Spleen } & \multicolumn{2}{|c|}{ Amniotic fluid } & \multicolumn{2}{|c|}{ Umbilical cord } \\
\hline & $\begin{array}{l}\text { L. infantum } \\
\text { (SQ mean) }\end{array}$ & $\begin{array}{l}\text { A. platys } \\
\text { (SQ mean) }\end{array}$ & $\begin{array}{l}\text { L. infantum } \\
\text { (SQ mean) }\end{array}$ & $\begin{array}{l}\text { A. platys } \\
\text { (SQ mean) }\end{array}$ & $\begin{array}{l}\text { L. infantum } \\
\text { (SQ mean) }\end{array}$ & $\begin{array}{l}\text { A. platys } \\
\text { (SQ mean) }\end{array}$ & $\begin{array}{l}\text { L. infantum } \\
\text { (SQ mean) }\end{array}$ & $\begin{array}{l}\text { A. platys } \\
\text { (SQ mean) }\end{array}$ & $\begin{array}{l}\text { L. infantum } \\
\text { (SQ mean) }\end{array}$ & $\begin{array}{l}\text { A. platys } \\
\text { (SQ mean) }\end{array}$ \\
\hline 820634 A & $-^{\mathrm{b}}$ & - & - & $2.83 \times 10^{-2}$ & - & - & - & - & - & - \\
\hline B & & & & $3.5 \times 10^{-2}$ & & & & & & \\
\hline 821717 A & - & - & - & - & - & - & - & - & - & - \\
\hline \multicolumn{11}{|l|}{ B } \\
\hline 828965 A & - & - & - & - & - & $1.65 \times 10^{-1}$ & - & - & - & - \\
\hline B & & & & & & $5.25 \times 10^{-2}$ & & & & \\
\hline $821240 \mathrm{~A}$ & - & - & - & - & - & $6.52 \times 10^{-2}$ & - & - & - & - \\
\hline \multicolumn{11}{|l|}{ B } \\
\hline 823993 A & - & - & - & - & - & - & - & - & - & - \\
\hline \multicolumn{11}{|l|}{ B } \\
\hline 42686 A & - & - & - & - & - & - & - & - & - & - \\
\hline \multicolumn{11}{|l|}{ B } \\
\hline 43077 A & - & - & - & - & - & - & - & - & $8.14 \times 10^{-4}$ & - \\
\hline \multicolumn{11}{|l|}{ B } \\
\hline $42783 \mathrm{~A}$ & - & - & - & - & - & - & - & - & - & - \\
\hline \multicolumn{11}{|l|}{ B } \\
\hline 43055 A & - & - & - & - & - & - & - & - & - & - \\
\hline \multicolumn{11}{|l|}{ B } \\
\hline $42825 A^{a}$ & - & - & - & - & - & - & - & - & - & - \\
\hline B & & & & & & & & & & \\
\hline
\end{tabular}

${ }^{\mathrm{a}}$ Dog used as negative control; ${ }^{\mathrm{b}}$ tissue $\mathrm{PPCR}$ negative for pathogen DNA

extraction of genomic DNA (Tables 1 and 2). Whole blood samples $(4 \mathrm{ml})$ were collected from the brachial or jugular veins of bitches and aliquots $(2 \mathrm{ml})$ were centrifuged at $1678 \mathrm{~g}$ for $10 \mathrm{~min}$, the sera were separated and stored in individually labelled Eppendorf tubes at $-20{ }^{\circ} \mathrm{C}$ until tested. An IFAT was performed using promastigotes of L. infantum zymodeme MON1 as antigen [19] to investigate previous exposure to Leishmania parasites. While under general anaesthesia, bone marrow samples were obtained from bitches by aspiration from the iliac crest using Rosenthal needles (16 or 18 Gauge) and stored at $-20{ }^{\circ} \mathrm{C}$ in individual tubes with $1 \mathrm{ml}$ of phosphate buffered saline (PBS) until subsequent testing. Aliquots of whole blood and bone marrow samples were smeared on slides and microscopically examined by staining with May-Grünwald-Giemsa Quick Stain (Bio Optica Spa, Italy). Skin tissue samples of approximately $0.5 \mathrm{~cm}^{2}$ were collected from the interscapular region of bitches and processed as described previously [19]. Uterus, ovaries and placenta biopsy samples were collected and stored in individual sterile tubes (Table 1).

Amniotic fluid $(1 \mathrm{ml})$ was collected for each foetus from the intact uterus using a sterile needle, and stored in individual tubes. Umbilical cord, spleen and liver samples $\left(1 \mathrm{~cm}^{2}\right)$ were collected by a sterile scalpel and stored in tubes containing PBS. The bone marrow samples were collected by cutting the tip of the sternum and stored in tubes with $1 \mathrm{ml}$ of PBS (Table 2).

\section{DNA extraction and parasite load determination}

Total DNA was extracted from whole blood, skin, uterus, ovaries, placenta, liver, spleen and umbilical cord samples using the Genomic DNA Purification Kit (Gentra Systems, Minnesota, USA), while genomic DNA from amniotic fluid and bone marrow samples was extracted using QIAampDNA Micro Kit (Qiagen, GmbH, Hilden, Germany). For each sample, two qPCR reactions were individually performed for the detection and quantification of $L$. infantum and $A$. platys nucleic acids, using primers and probes targeting, respectively, the kinetoplast minicircle DNA (kDNA) and 16S rRNA gene, as described previously [18, 23]. DNA extracted from lymph nodes and whole blood from $L$. infantum and $A$. platys-infected dogs were included as positive controls. Quantification of DNA of L. infantum and A. platys was performed using a 10-fold dilution series of standard 
DNA from promastigotes (log phase concentration, $1.7 \times$ $10^{6}$ parasites $/ \mathrm{ml}$ ) of $L$. infantum (zymodeme MON-1) and from A. platys-infected blood with a concentration of $5.6 \times$ $10^{5}$ infected platelets/100 $\mu$ l. The detection limits of the qPCRs were assessed using serial dilutions from $1.7 \times 10^{-2}$ to $1.7 \times 10^{-7}$ parasites (L. infantum) and from $2.24 \times 10^{2}$ to $2.24 \times 10^{-6}$ infected platelets (A. platys) per reaction $(2 \mu \mathrm{l}$ of DNA template), respectively.

\section{Results}

Dogs included in the study, with the exception of negative controls, were serologically positive for $L$. infantum (IFAT titre up to 1:160) and for A. platys by pathogen DNA amplification from whole blood, bone marrow and skin samples (both L. infantum and A. platys) (Tables 1 , 3 and 4). Eighteen out of 54 (33.3\%) tissue samples collected from pregnant bitches were positive to L. infantum by qPCR; of these, only one placental tissue sample was positive for this parasite, at a detected load of $1.2 \times$ $10^{-3} /$ PCR reaction (Tables 1 and 3 ). No uterine and ovarian samples were positive for L. infantum (Tables 1 and 3). Of the 100 foetal samples collected, only one umbilical cord was L. infantum-positive, albeit with a low parasite load of $8.14 \times 10^{-4} / \mathrm{PCR}$ reaction (Table 2 ). Conversely, 17/45 (37.8 \%) tissue samples collected from non-pregnant bitches were qPCR positive for $L$. infantum (Tables 1 and 4), with the highest parasite load detected in ovarian and uterine samples (i.e. up to $3.09 \times 10$ and 7.51/PCR reaction, respectively) (Table 4).

Sixteen out of $54(29.6 \%)$ tissues from pregnant bitches were qPCR positive for $A$. platys, including three uterine, two ovarian and one placental sample with parasite loads ranging from $6.2 \times 10^{-3}$ to $2.73 \times 10^{-1} / \mathrm{PCR}$ reaction (Tables 1 and 3 ). Of the foetal tissues samples, five tested positive for $A$. platys ( $n=2$ liver; $n=3$ spleen) with parasite loads ranging from $2.83 \times 10^{-2}$ to $1.65 \times 10^{-1}$ / PCR reaction (Table 2). Of the 45 tissue samples collected from non-pregnant bitches (Tables 1 and 4), seven uteri and six ovaries scored qPCR positive for $A$. platys, with parasite loads ranging from $6.8 \times 10^{-2}$ to $2.05 / \mathrm{PCR}$ reaction (Tables 1 and 4).

Ten bitches ( $n=6$ pregnant; $n=4$ non-pregnant) were shown to be co-infected with both pathogens (Tables 1 , 3 and 4). Two uterine samples from non-pregnant bitches were $\mathrm{qPCR}$ positive for $L$. infantum and $A$. platys, with parasite loads ranging from $2.17 \times 10^{-3}$ to $2.32 \times 10^{-3} / \mathrm{PCR}$ reaction and from $6.8 \times 10^{-2}$ to $2.05 /$ PCR reaction, respectively (Table 4 ). Tissues from dogs selected as negative controls on the basis of cytological examination of whole blood and bone marrow were qPCR negative for both pathogens (Tables 3 and 4).

\section{Discussion}

This study provides new data regarding vertical transmission of L. infantum and A. platys in naturally infected dogs. Based on the samples examined, vertical transmission of $L$. infantum from an infected bitch to the offspring could be less frequent during the first half of gestation (i.e. 25-35 days). Indeed, a previous study investigating vertical transmission of $L$. infantum in eight bitches and their 53 foetuses during late pregnancy (i.e. 50-60 days) showed that $32 \%$ of foetuses and $49 \%$ of the corresponding placentas were PCR positive for this pathogen [24]. In contrast, the detection of L. infantum DNA in only one placenta, moreover with a low parasite load (i.e. $1.21 \times 10^{-3}$ ), supports our hypothesis that this pathogen is unlikely to be transmitted during this phase of gestation. However, based upon the qPCR findings from non-pregnant bitches, L. infantum may be able to spread to the ovary, uterus and blood, with the former tissues displaying a higher

Table 3 Real-time PCR detection and quantification of Leishmania infantum and Anaplasma platys DNA. in tissue samples from pregnant bitches. Starting Quantity (SQ) mean value of parasite load per PCR reaction

\begin{tabular}{|c|c|c|c|c|c|c|c|c|c|c|c|c|}
\hline \multirow[t]{2}{*}{ Dogs } & \multicolumn{2}{|l|}{ Blood } & \multicolumn{2}{|c|}{ Bone marrow } & \multicolumn{2}{|l|}{ Skin } & \multicolumn{2}{|l|}{ Uterus } & \multicolumn{2}{|l|}{ Ovary } & \multicolumn{2}{|l|}{ Placentae } \\
\hline & $\begin{array}{l}\text { L. infantum } \\
\text { (SQ mean) }\end{array}$ & $\begin{array}{l}\text { A. platys } \\
\text { (SQ mean) }\end{array}$ & $\begin{array}{l}\text { L. infantum } \\
\text { (SQ mean) }\end{array}$ & $\begin{array}{l}\text { A. platys } \\
\text { (SQ mean) }\end{array}$ & $\begin{array}{l}\text { L. infantum } \\
\text { (SQ mean) }\end{array}$ & $\begin{array}{l}\text { A. platys } \\
\text { (SQ mean) }\end{array}$ & $\begin{array}{l}\text { L. infantum } \\
\text { (SQ mean) }\end{array}$ & $\begin{array}{l}\text { A. platys } \\
\text { (SQ mean) }\end{array}$ & $\begin{array}{l}\text { L. infantum } \\
\text { (SQ mean) }\end{array}$ & $\begin{array}{l}\text { A. platys } \\
\text { (SQ mean) }\end{array}$ & $\begin{array}{l}\text { L. infantum } \\
\text { (SQ mean) }\end{array}$ & $\begin{array}{l}\text { A. platys } \\
\text { (SQ mean) }\end{array}$ \\
\hline 820634 & $-^{b}$ & $2.31 \times 10^{-1}$ & - & $3.50 \times 10^{-2}$ & $2.36 \times 10^{-3}$ & - & - & $2.78 \times 10^{-2}$ & - & - & - & - \\
\hline 821717 & - & - & $2.68 \times 10^{-3}$ & - & $1.50 \times 10^{-3}$ & - & - & - & - & - & - & $6.2 \times 10^{-3}$ \\
\hline 828965 & - & - & $2.61 \times 10^{-3}$ & $3.36 \times 10^{2}$ & $5.70 \times 10^{-3}$ & $3.52 \times 10$ & - & $2.75 \times 10^{-2}$ & - & - & - & - \\
\hline 821240 & - & $3.85 \times 10^{-2}$ & $2.08 \times 10^{-3}$ & $2.31 \times 10^{-1}$ & $8.28 \times 10^{-3}$ & $3.75 \times 10^{-2}$ & - & - & - & $2.27 \times 10^{-2}$ & $1.21 \times 10^{-3}$ & - \\
\hline 823993 & - & - & $3.43 \times 10^{-3}$ & - & $3.57 \times 10^{-3}$ & - & - & - & - & - & - & - \\
\hline 42686 & $1.40 \times 10^{-3}$ & - & $6.14 \times 10^{-4}$ & - & $5.54 \times 10^{-3}$ & - & - & - & - & - & - & - \\
\hline 43077 & - & $1.68 \times 10^{-1}$ & - & $2.91 \times 10^{-1}$ & $3.79 \times 10^{-3}$ & - & - & $1.88 \times 10^{-1}$ & - & $2.73 \times 10^{-1}$ & - & - \\
\hline 42783 & - & - & $1.52 \times 10^{-3}$ & - & $9.02 \times 10^{-3}$ & $2.83 \times 10^{-2}$ & - & - & - & - & - & - \\
\hline 43055 & - & - & $2.70 \times 10^{-4}$ & - & $5.88 \times 10^{-4}$ & - & - & - & - & - & - & - \\
\hline $42825^{a}$ & - & - & - & - & - & - & - & - & - & - & - & - \\
\hline
\end{tabular}

${ }^{a}$ Negative control; ${ }^{b} \mathrm{qPCR}$ negative for pathogen DNA 
Table 4 Real-time PCR detection and quantification of Leishmania infantum and Anaplasma platys DNA in tissue samples from nonpregnant bitches. Starting Quantity (SQ) mean value of parasite load per PCR reaction

\begin{tabular}{|c|c|c|c|c|c|c|c|c|c|c|}
\hline \multirow[t]{2}{*}{ Dogs } & \multicolumn{2}{|l|}{ Blood } & \multicolumn{2}{|c|}{ Bone marrow } & \multicolumn{2}{|l|}{ Skin } & \multicolumn{2}{|l|}{ Uterus } & \multicolumn{2}{|l|}{ Ovary } \\
\hline & $\begin{array}{l}\text { L. infantum } \\
\text { (SQ mean) }\end{array}$ & $\begin{array}{l}\text { A. platys } \\
\text { (SQ mean) }\end{array}$ & $\begin{array}{l}\text { L. infantum } \\
\text { (SQ mean) }\end{array}$ & $\begin{array}{l}\text { A. platys } \\
\text { (SQ mean) }\end{array}$ & $\begin{array}{l}\text { L. infantum } \\
\text { (SQ mean) }\end{array}$ & $\begin{array}{l}\text { A. platys } \\
\text { (SQ mean) }\end{array}$ & $\begin{array}{l}\text { L. infantum } \\
\text { (SQ mean) }\end{array}$ & $\begin{array}{l}\text { A. platys } \\
\text { (SQ mean) }\end{array}$ & $\begin{array}{l}\text { L. infantum } \\
\text { (SQ mean) }\end{array}$ & $\begin{array}{l}\text { A. platys } \\
\text { (SQ mean) }\end{array}$ \\
\hline 809546 & $2.44 \times 10^{-3}$ & - & $2.19 \times 10^{-2}$ & - & $1.63 \times 10$ & - & $2.37 \times 10^{-1}$ & - & $3.03 \times 10^{-2}$ & - \\
\hline 43117 & $2.41 \times 10^{-1}$ & - & 4.93 & - & $8.99 \times 10^{-3}$ & - & 7.51 & - & $3.09 \times 10$ & - \\
\hline 42853 & $-{ }^{b}$ & - & - & $2.25 \times 10^{-1}$ & - & $3.29 \times 10^{-2}$ & - & $3.91 \times 10^{-2}$ & - & - \\
\hline 43017 & - & - & - & - & - & - & - & $2.24 \times 10^{-1}$ & - & $5.83 \times 10^{-2}$ \\
\hline 43115 & - & - & $2.01 \times 10^{-1}$ & 1.35 & 2.24 & - & $2.32 \times 10^{-3}$ & 2.05 & - & 1.55 \\
\hline 31585 & - & - & - & - & - & - & - & $1.20 \times 10^{-1}$ & - & $4.80 \times 10^{-2}$ \\
\hline 42641 & - & - & - & $7.80 \times 10^{-2}$ & - & - & $2.17 \times 10^{-3}$ & $6.80 \times 10^{-2}$ & - & $5.95 \times 10^{-2}$ \\
\hline 31339 & - & - & $2.50 \times 10^{-3}$ & $1.90 \times 10^{-1}$ & - & - & - & $2.81 \times 10^{-1}$ & - & $5.78 \times 10^{-2}$ \\
\hline 830178 & - & - & $1.20 \times 10^{-2}$ & - & $2.59 \times 10^{-2}$ & - & - & $1.90 \times 10^{-1}$ & - & 1.88 \\
\hline $31956^{a}$ & - & - & - & - & - & - & - & - & - & - \\
\hline
\end{tabular}

${ }^{a}$ Negative control; ${ }^{b}$ PPCR negative for pathogen DNA

parasite load (i.e. $3.09 \times 10$ ) compared to the latter (i.e. $\left.2.41 \times 10^{-1}\right)$. Nevertheless, albeit promising, our preliminary data needs confirming in studies including a significantly larger number of infected bitches.

The contrasting findings observed for L. infantum between pregnant and non-pregnant bitches might be related to the hormonal changes associated with pregnancy and the different stages of the reproductive cycle. Increased oestrogen concentration in nonpregnant bitches may cause hyperaemia of the uterus and ovary tissues [25], which in turn may have been responsible for the increase in pathogen concentration in these sites. Alternatively, the fact that the uterus and ovary tissues of pregnant bitches were negative for L. infantum could be associated to the high blood flow resistance that characterises the canine placenta throughout the first half of gestation, and that progressively decreases in conjunction with the development of the foetal and placental circulation throughout the second half of gestation [26].

In previous studies, DNA from $L$. infantum was detected from foetal tissue samples (i.e. bone marrow, liver and spleen) over the last ten days of pregnancy (i.e. 5060 days) and in newborn puppies [7, 10, 12, 24, 27, 28], but not from the uteri of infected pregnant bitches [27]. The detection of $L$. infantum amastigotes mostly in lymphoreticular organs (e.g. spleen, bone marrow, lymph nodes and liver) of late-gestation foetuses or newborn puppies [24], could mirror the distribution of parasites in tissues and organs of adult dogs. Therefore, it is tempting to speculate that the lack of L. infantum-PCR positive samples from foetuses examined in the present study may be linked to the immature state of the foetal immune system in early gestation. Lymphocytic infiltration of the foetal lymph nodes and spleen becomes evident from 45 to 52 days of gestation, which temporally corresponds to the development of the bone marrow that, at this time, contains a large number of hematopoietic stem cells [29].

This study provides first evidence supporting the hypothesis that $A$. platys may be vertically transmitted from the pregnant bitch to the offspring. Indeed, liver, spleen and uterine, ovarian, and placental tissues of foetuses and mothers positive for this pathogen were also positive for $A$. platys, with comparable pathogen loads (i.e. $2.83 \times 10^{-2}$ in foetuses and $2.78 \times 10^{-2}$ in mothers). The presence of the marginal haemophagous zones in the dog placenta, filled with extravasated maternal blood [30] could justify the detection of $A$. platys-infected platelets.

The above factors may also justify the finding of a higher $A$. platys load (i.e. 2.05) than that of L. infantum (i.e. $2.32 \times 10^{-3}$ ) in the uterus of co-infected nonpregnant bitches in this study. The possibility of vertical transmission of $A$. platys in dogs is in agreement with knowledge of this event occurring for Anaplasma marginale and Anaplasma phagocytophilum in cattle $[31,32]$, whereas the minimal data relative to in utero transmission of $A$. phagocytophilum in dogs [33] did not support transplacental transmission. Controlled laboratory studies involving puppies from bitches infected with $A$. platys should be addressed to better understand this transmission pattern. To mimic a natural infection, bitches should be infected with $A$. platys by blood transfusion or by a competent vector.

However, confirmatory studies on naturally infected pregnant bitches (both symptomatic and asymptomatic) in early (25-35 days) and late pregnancy (50-60 days) and on their foetuses, need to be carried out in order to confirm or confute this hypothesis. 


\section{Conclusion}

Based on the results of the present study, transmission of L. infantum from infected mothers to their offspring appears unlikely or less frequent during the first half of gestation, whereas vertical transmission may occur during the later stages of gestation. In contrast, vertical transmission of $A$. platys may occur during the early stages of gestation, and throughout its entire course. If confirmed, these findings will pose additional challenges for the development of disease control strategies in both endemic and non-endemic areas.

\section{Competing interests}

The authors declare that they have no competing interests.

\section{Authors' contributions}

MSL and DO conceived the study, analysed the data and drafted the manuscript. RPL collected samples and carried out the surgical procedures. MSL performed the molecular analysis. FDT, DdC, CC, GC, EB critically reviewed the manuscript. All authors read and approved the final version of the manuscript.

\section{Acknowledgements}

The paper has been sponsored by Bayer Animal Health in the framework of the 11th CVBD World Forum Symposium.

\section{Author details \\ 'Dipartimento di Medicina Veterinaria, Università degli Studi di Bari, Valenzano, Italy. ${ }^{2}$ Aggeu Magalhães Research Centre, Oswaldo Cruz Foundation, Recife, Pernambuco, Brazil. '3 Department of Veterinary Medicine, University of Cambridge, Cambridge, UK. ${ }^{4}$ Istituto Zooprofilattico Sperimentale delle Venezie, Legnaro, Padova, Italy. ${ }^{5}$ Intracellular Pathogens Research Laboratory, Center for Comparative Medicine, College of Veterinary Medicine, North Carolina State University, Raleigh, NC, USA.}

Received: 26 February 2016 Accepted: 27 April 2016

Published online: 10 May 2016

\section{References}

1. Otranto D, Dantas-Torres F, Breitschwerdt EB. Managing canine vector-borne diseases of zoonotic concern: part one. Trends Parasitol. 2009;25:157-63.

2. Killick-Kendrick R. Phlebotomine vectors of the leishmaniases: a review. Med Vet Entomol. 1990;4:1-24.

3. Owens SD, Oakley DA, Marryott K, Hatchett W, Walton R, Nolan TJ, et al. Transmission of visceral leishmaniasis through blood transfusions from infected English foxhounds to anemic dogs. J Am Vet Med Assoc. 2001;219: 1076-83.

4. Giger U, Oakley DA, Owens SD, Schantz P. Leishmania donovani transmission by packed RBC transfusion to anemic dogs in the United States. Transfusion. 2002;42:381-3.

5. Benites AP, Fernandes CE, Brum KB, Abdo MAGS. Presença de formas amastigotas de Leishmania chagasi e perfil leucocitário no aparelho reprodutivo de cães. Pesq Vet Bras. 2011;31:72-7.

6. Turchetti AP, Souza TD, Paixão TA, Santos RL. Sexual and vertical transmission of visceral leishmaniasis. J Infect Dev Ctries. 2014;8:403-7.

7. Masucci M, De Majo M, Contarino RB, Borruto G, Vitale F, Pennisi MG. Canine leishmaniasis in the newborn puppy. Vet Res Commun. 2003;27:771-4.

8. Rosypal AC, Lindsay DS. Non-sand fly transmission of a North American isolate of Leishmania infantum in experimentally infected balb/c mice. J Parasitol. 2005:91:1113-5.

9. Rosypal AC, Troy GC, Zajac AM, Frank G, Lindsay DS. Transplacental transmission of a North American isolate of Leishmania infantum in an experimentally infected beagle. J Parasitol. 2005;91:970-2.

10. Boggiatto PM, Gibson-Corley KN, Metz K, Gallup JM, Hostetter JM, Mullin K, et al. Transplacental trasmission of Leshmania infantum as a means for continued disease incidence in North America. PLoS Negl Trop Dis. 2011;5: e1019.
11. Naucke TJ, Lorentz S. First report of venereal and vertical transmission of canine leishmaniosis from naturally infected dogs in Germany. Parasit Vectors. 2012;5:67.

12. Ben Slimane T, Chouihi E, Ben Hadj Ahmed S, Chelbi I, Barhoumi W, Cherni $S$, et al. An investigation on vertical transmission of Leishmania infantum in experimentally infected dogs and assessment of offspring's infectiousness potential by xenodiagnosis. Vet Parasitol. 2014;206:282-6.

13. Gibson-Corley KN, Hostetter JM, Hostetter SJ, Mullin K, Ramer-Tait AE, Boggiatto PM, et al. Disseminated Leishmania infantum infection in two sibling foxhounds due to possible vertical transmission. Can Vet J. 2008;49: 1005-8.

14. Petersen CA. Leishmaniasis, an emerging disease found in companion animals in the United States. Top Companion Anim Med. 2009;24:182-8.

15. Inokuma H, Raoult D, Brouqui P. Detection of Ehrlichia platys DNA in brown dog ticks (Rhipicephalus sanguineus) in Okinawa Island, Japan. J Clin Microbiol. 2000;38:4219-21

16. Sanogo YO, Davoust B, Inokuma H, Camicas $J$, Parola P, Brouqui P. First evidence of Anaplasma platys in Rhipicephalus sanguineus (Acari: Ixodida) collected from dogs in Africa. Onderstepoort J Vet Res. 2003, 70:205-12.

17. Latrofa MS, Dantas-Torres F, Giannelli A, Otranto D. Molecular detection of tick-borne pathogens in Rhipicephalus sanguineus group ticks. Ticks Tick Borne Dis. 2014;5:943-6.

18. Ramos RA, Latrofa MS, Giannelli A, Lacasella V, Campbell BE, DantasTorres F, et al. Detection of Anaplasma platys in dogs and Rhipicephalus sanguineus group ticks by a quantitative real-time PCR. Vet Parasitol. 2014;205:285-8

19. Otranto D, de Caprariis D, Lia RP, Tarallo V, Lorusso V, Testini G, et al. Prevention of endemic canine vector-borne diseases using imidacloprid $10 \%$ and permethrin $50 \%$ in young dogs: a longitudinal field study. Vet Parasitol. 2010;172:323-32

20. Otranto D, Dantas-Torres F, de Caprariis D, Di Paola G, Tarallo VD, Latrofa MS, et al. Prevention of canine leishmaniosis in a hyper-endemic area using a combination of $10 \%$ imidacloprid/4.5 \% flumethrin. PLoS One. 2013;8: e56374.

21. Dantas-Torres F, Capelli G, Giannelli A, Ramos RA, Lia RP, Cantacessi C, et al. Efficacy of an imidacloprid/flumethrin collar against fleas, ticks and tickborne pathogens in dogs. Parasit Vectors. 2013;6:245.

22. Noden DM, De Lahunta A. Embryology of domestic animals: Developmental mechanisms and malformations. Baltimore: Williams \& Wilkins; 1985. p. 367

23. Dantas-Torres F, Latrofa MS, Otranto D. Quantification of Leishmania infantum DNA in females, eggs and larvae of Rhipicephalus sanguineus. Parasit Vectors. 2011:4:56.

24. Pangrazio KK, Costa EA, Amarilla SP, Cino AG, Silva TM, Paixao TA, et al. Tissue distribution of Leishmania cagasi and lesion in transplacentally infected fetuses from symptomatic and asymptomatic naturally infected bitches. Vet Parasitol. 2009:165:327-31.

25. Concannon PW. Reproductive cycles of the domestic bitch. Anim Reprod Sci. 2011;124:200-10.

26. Di Salvo P, Bocci F, Zelli R, Polisca A. Doppler evaluation of maternal and fetal vessels during normal gestation in the bitch. Res Vet Sci. 2006:81:382-8.

27. da Silva SM, Ribeiro VM, Ribeiro RR, Tafuri WL, Melo MN, Marques Michalick MS. First report of vertical transmission of Leishmania infantum in a naturally infected bitch from Brazil. Vet Parasitol. 2009;166:159-62.

28. Vida B, Toepp A, Schaut RG, Esch KJ, Juelsgaard R, Shimak RM, et al. Immunologic progression of canine leishmaniosis following vertical transmission in United States dogs. Vet Immunol Immunopathol. 2016;169:34-8.

29. Felsburg PJ. Overview of immune system development in the dog: comparison with humans. Hum Exp Toxicol. 2002;21:487-92.

30. Furukawa S, Kuroda Y, Sugiyama A. A comparison of the histological structure of the placenta in experimental animals. J Toxicol Pathol. 2014;27:11-8.

31. Pusterla N, Braun U, Wolfensberger C, Lutz H. Intrauterine infection with Ehrlichia phagocytophila in a cow. Vet Rec. 1997;141:101-2.

32. Grau HE, Cunha Filho NA, Pappen FG, Farias NA. Transplacental transmission of Anaplasma marginale in beef cattle chronically infected in southern Brazil. Rev Bras Parasitol Vet. 2013;22:189-93.

33. Plier ML, Breitschwerdt EB, Hegarty BC, Kidd LB. Lack of evidence for perinatal transmission of canine granulocytic anaplasmosis from a bitch to her offspring. J Am Anim Hosp Assoc. 2009;45:232-8. 